\title{
Sensitivity Loss in Early Glaucoma Can Be Mapped to an Enlargement of the Area of Complete Spatial Summation
}

\author{
Tony Redmond, ${ }^{1,2}$ David F. Garway-Heath, ${ }^{2}$ Margarita B. Zlatkova, ${ }^{1}$ and \\ Roger S. Anderson ${ }^{1,2}$
}

\begin{abstract}
Purpose. The area of complete spatial summation (Ricco's area) is the largest stimulus size for which area $\times$ intensity is constant at threshold. The authors sought to investigate whether Ricco's area changes in early glaucoma to account for the decreased visual signal/noise ratio that may accompany retinal ganglion cell loss.
\end{abstract}

Methods. Spatial summation functions were measured, and Ricco's area was determined at four $10^{\circ}$ retinal locations in 24 patients with early glaucoma (total deviation at test locations, mean, $-1.3 \mathrm{~dB}$; range, $+2 \mathrm{~dB}$ to $-8 \mathrm{~dB}$ ) and 26 age-similar healthy subjects under achromatic and S-cone isolation conditions. Achromatic grating resolution acuity was measured at the same locations to estimate functional ganglion cell density.

RESUlts. Ricco's area was enlarged in patients compared with controls for both achromatic (enlarged by: superior field, 0.57 $\log$ units, $P<0.01$; inferior field, $0.72 \log$ units, $P<0.01)$ and chromatic (enlarged by: superior field, $0.26 \log$ units, $P<0.01$; inferior field, $0.25 \log$ units, $P=0.065$ ) stimuli, with negligible vertical summation curve shifts along the intensity axis. Resolution acuity was significantly reduced in glaucoma patients in both hemifields $(P<0.001)$. There was a weak, but significant, relationship between Ricco's area and resolution acuity.

Conclusions. Enlargement of Ricco's area completely compensates for reduced perimetric sensitivity in early glaucoma to maintain constant threshold at Ricco's area, suggesting an increase in signal pooling in response to ganglion cell loss. The rightward displacement of the spatial summation curve indicates that perimetric stimuli should be capable of modulating in size as well as/instead of contrast, which may boost the glaucoma signal within measurement noise. (Invest Ophthalmol Vis Sci. 2010;51:6540 - 6548) DOI:10.1167/iovs.10-5718

From the ${ }^{1}$ Vision Science Research Group, School of Biomedical Sciences, University of Ulster, Coleraine, Northern Ireland, United Kingdom; and the ${ }^{2}$ NIHR Biomedical Research Centre for Ophthalmology, Moorfields Eye Hospital NHS Foundation Trust and UCL Institute of Ophthalmology, London, United Kingdom.

Presented in part at the annual meeting of the Association for Research in Vision and Ophthalmology, Fort Lauderdale, Florida, May 2010 .

Supported by a PhD studentship from the Department of Employment and Learning, Northern Ireland (TR) and by the NIHR Biomedical Research Centre for Ophthalmology, Moorfields Eye Hospital NHS Foundation Trust and UCL Institute of Ophthalmology (TR).

Submitted for publication April 15, 2010; revised June 14, 2010; accepted July 7, 2010.

Disclosure: T. Redmond, None; D.F. Garway-Heath, None; M.B. Zlatkova, None; R.S. Anderson, None

Corresponding author: Tony Redmond, Glaucoma Research Unit, Moorfields Eye Hospital, 162 City Road, London, EC1V 2PD, United Kingdom; tony.redmond@moorfields.nhs.uk.
S tandard automated perimetry (SAP) is routinely used in $\mathcal{O}$ ophthalmic clinics across the world for the detection, evaluation, and monitoring of neural damage to the visual pathway, particularly in conditions such as glaucoma. Glaucoma is characterized by a loss of retinal ganglion cells, which can be observed directly using histologic techniques ${ }^{1-6}$ or indirectly by measuring axonal bundle thickness using in vivo imaging techniques. ${ }^{6-13}$ In the past few decades, many studies involving SAP have attempted to relate measurements of sensitivity in glaucoma with retinal structure using both histologic and in vivo imaging techniques ${ }^{1-4,6,13-18}$ in an attempt to better understand how glaucoma patients lose vision. It has become clear that such a goal is not a simple one, and a full understanding of the structure/function relationship likely depends on, among other factors, the stimulus modulation scale used, ${ }^{16,19}$ spatial summation, ${ }^{15,20-22}$ and nonaxonal retinal nerve fiber layer components. ${ }^{13}$

It is well known that perimetric sensitivity declines with progressive ganglion cell death in glaucoma. It has also been well established that the relationship between ganglion cell density and perimetric sensitivity is not monotonic over the entire course of the disease. ${ }^{15,20,22}$ Among many other factors, consideration of spatial summation should be made when interpreting thresholds determined during conventional perimetry. It is known that the area of complete spatial summation increases with retinal eccentricity ${ }^{23-25}$ and that changes to this area occur with background adaptation level. ${ }^{24-28}$ Considering Ricco's law and the classical spatial summation curve it is apparent that, in the normal eye, thresholds for conventional Goldmann III stimuli (area $=-0.83 \log \mathrm{deg}^{2}$ ) in SAP are determined by complete spatial summation only for retinal eccentricities greater than approximately $15^{\circ}$. This is because the stimulus size is smaller than Ricco's area for those retinal regions. Within $15^{\circ}$, thresholds for SAP are determined by probability summation because stimuli are larger than Ricco's area. If one uses a larger stimulus for conventional perimetry (e.g., Goldman V), then thresholds will be determined by probability summation for a greater region of the retina under test. It is clear that the relative size of Ricco's area and the stimulus size used are important when determining and interpreting threshold values from SAP.

The exact physiological mechanism underlying Ricco's area is still heavily debated ${ }^{22,24,25,28-31}$; however, some studies suggest that it changes with retinal eccentricity to maintain a constant number of underlying ganglion cells. ${ }^{24,25}$ Swanson et al. $^{20}$ have devised a two-stage neural model to describe the relationship between perimetric sensitivity and local ganglion cell number in healthy observers. This model was devised after consideration of differences in ganglion cell density with retinal eccentricity and of differences in pooling by second-stage spatial filters at a higher visual site. Crucially, it also acknowledges that although Ricco's area enlarges with eccentricity, 
sensitivity at Ricco's area remains constant. ${ }^{23}$ Although it is known that a physiological change in spatial scale occurs with increased retinal eccentricity, ${ }^{20,23,32}$ when ganglion cell density declines, it is unclear whether Ricco's area changes as a result of pathologically reduced ganglion cell density at any given retinal location, such as in glaucoma. We have previously found (see accompanying paper ${ }^{33}$ ) that there is no observable net change in Ricco's area as a function of age. However, several published findings point toward an alteration of spatial summation and Ricco's area in glaucoma. Fellman et al. ${ }^{34}$ showed that when lower background adaptation levels were used for their experimental task, disproportionate improvements in contrast sensitivity were observed for different retinal eccentricities and between healthy observers and glaucoma patients. Anderson ${ }^{21}$ suggested that this may be because of an alteration in spatial summation mechanisms in the receptive fields of retinal ganglion cells in line with the hypothesis of Glezer. ${ }^{28}$ Fellman et al. ${ }^{34}$ also showed that in glaucoma patients, an increase in stimulus size caused a greater increase in retinal sensitivity than increasing contrast. In healthy observers, however, they found that increasing contrast improved retinal sensitivity more than increasing stimulus size. They concluded that their result of an increased sensitivity to larger stimuli could be explained by normal spatial summation involving a recruitment of adjacent retinal areas that might have been more "normal" than the test location. In addition, they noted that some results could only be explained by "pathologic" spatial summation. Several other studies have considered changes in spatial summation in glaucoma. ${ }^{21,35-37}$ Dannheim and Drance ${ }^{35}$ measured perimetric thresholds for a range of stimulus sizes and noted no abnormality of spatial summation between damaged and normal retinal areas in glaucomatous eyes, as determined by Goldmann perimetry. Conversely, Felius et al. ${ }^{36}$ demonstrated an enlargement of the critical summation area in a small number of glaucoma patients compared with healthy controls; however, this study had a reduced dynamic range over which Ricco's area could be measured, and, thus, a moderate proportion of the data could not be included in the analysis. This proved particularly difficult for the S-cone pathway.

Although the two-stage neural model described by Swanson et al. ${ }^{20}$ relates perimetric sensitivity and ganglion cell numbers in consideration of changes in spatial summation with eccentricity in healthy observers, Anderson ${ }^{21}$ proposed that a similar mechanism might exist in glaucoma whereby Ricco's area would enlarge as the disease progresses, as it does with eccentricity in healthy observers. For locations within $15^{\circ}$ of the fovea, this would mean that initial ganglion cell losses would be accompanied by small changes in decibel sensitivity until progressive ganglion cell loss causes Ricco's area to enlarge to the equivalent of the Goldmann III stimulus (or larger); at that point, thresholds would be determined by complete summation and would demonstrate a greater rate of change in sensitivity for the same rate of ganglion cell loss. Bearing in mind that the area of the Goldmann III stimulus is generally larger than Ricco's area for much of the central retina (within $15^{\circ}$ of the fovea), considerable ganglion cell loss may be required before a glaucomarelated increase in Ricco's area is sufficient for threshold to be determined by complete spatial summation, and, for similar reasons, functional damage may go largely undetected in the central visual field for SAP stimuli until the condition becomes more advanced. Indeed, this argument can also be applied to the S-cone pathway and short-wavelength automated perimetry (SWAP) using a Goldman V stimulus.

The purpose of the present study was to investigate the nature of spatial summation in patients with glaucoma and, in particular, to investigate how Ricco's area changes in the very early stages of the disease with respect to age-similar healthy observers. As in the accompanying study, ${ }^{33}$ there are three possible outcomes. First, there may be an entirely upward shift of the spatial summation curve in glaucoma patients compared with age-similar healthy subjects (as has been shown as a function of age in the accompanying paper ${ }^{33}$ ), with no apparent change in Ricco's area. In such a case, thresholds for all stimulus sizes would be elevated equally. The second possibility is an entirely rightward shift of the spatial summation curve with no upward shift. In this case, one should observe a disproportionate elevation in threshold for small stimuli compared with larger stimuli. The third possibility is that of both an upward and a rightward shift of the spatial summation curve. In this scenario, an enlargement of Ricco's area would be observed in addition to an elevated threshold at Ricco's area in glaucoma patients compared to age-similar healthy subjects.

Measurements of peripheral grating resolution acuity allow one to obtain estimates of local ganglion cell density ${ }^{38,39}$ for each subject and to observe how Ricco's area values change with decreasing ganglion cell sampling density in glaucoma. Given that glaucoma is characterized by a pathologic loss of retinal ganglion cells, the range of retinal ganglion cell sampling density over which Ricco's area estimates can be made should be greater than that reported in our accompanying study $^{33}$; it may, therefore, be possible to identify the relationship between Ricco's area and ganglion cell density. The present study is thus the first to investigate the relationship between Ricco's area and estimates of ganglion cell density at the same retinal location and under the same adaptive conditions for each subject.

\section{Subjects ANd Methods}

\section{Subjects}

Twenty-four white European patients with early glaucoma (mean, 63 years; range, 46-78 years) and 26 age-similar white European healthy subjects (mean, 62 years; range, 51-77 years) were recruited for this study. Healthy subjects were selected by age matching from the same cohort, as described in the accompanying paper and with the same inclusion/exclusion criteria for that study. ${ }^{33}$ of the 24 patients, 13 had previously received diagnoses of primary open angle glaucoma and 11 had previously received diagnoses of normal tension glaucoma by the hospital eye service. All subjects had best-corrected visual acuity $>6 / 9$ $(20 / 30)$, intraocular pressure (IOP) $<21 \mathrm{~mm} \mathrm{Hg}$, spherical refractive error between +6.00 DS and $-6.00 \mathrm{DS}$, and astigmatism $<1.25 \mathrm{DC}$ in the test eye, as determined by a full eye examination. Refraction was performed in all participants objectively (by retinoscopy) and subjectively before the commencement of experimental tests. None of the patients had any other ocular or systemic condition known to affect vision. None had any media opacity that was abnormal for their particular age group, as determined using slit lamp biomicroscopy and retinoscopy. None had any history of glaucoma surgery or laser procedure in the test eye. Values for rim area were outside normal limits for all glaucoma patients by Moorfields Regression Analysis (Heidelberg Retina Tomograph [HRT II]; Heidelberg, Germany). Values were within normal limits for all healthy subjects. Early glaucomatous field loss was defined as a mean deviation (MD) cutoff value of $\geq-8 \mathrm{~dB}$ by SAP (Humphrey Field Analyzer II; Carl Zeiss Meditec Inc., Dublin, CA; 24-2 test pattern). Although all patients met the MD criterion of $\geq-8$ $\mathrm{dB}$, some patients showed marked visual field loss near the retinal locations tested in the present study. Therefore, we also excluded patients who had a total deviation (TD) value of $>-8 \mathrm{~dB}$ in more than two of the four locations closest to the study test locations (coordinates in degrees: 9,$3 ;-9,3 ;-9,-3 ; 9,-3)$. Age-similar healthy subjects were required to have normal visual fields with no sign of pathology. Subjects' pupils were dilated with 1 drop of tropicamide hydrochloride (1\%) before the experiments. In all cases a pupil diam- 
eter $\geq 8 \mathrm{~mm}$ was achieved. Recruitment of patients and subjects adhered to the tenets of the Declaration of Helsinki.

\section{Apparatus and Stimuli}

Apparatus, stimuli, method of correction of refractive error, and psychophysical procedure were identical with those used in the accompanying paper. ${ }^{33}$ Briefly, achromatic contrast detection thresholds were determined for six differently sized circular increments using a Yes/No criterion and a best-PEST thresholding algorithm ${ }^{40}$ on a $\gamma$-corrected 21-inch grayscale monitor (Philips Fimi MGD-403; Ampronix, Irvine, CA; pixel RGB resolution, $1280 \times 965$; frame rate, $73 \mathrm{~Hz}$ ) using a visual stimulus generator card (Cambridge Research Systems, Rochester, UK) and software (Psycho v2.0; Cambridge Research Systems) to drive the stimuli. Contrast thresholds were measured for chromatic stimuli under S-cone isolation (Stiles two-color threshold method) on a $\gamma$-corrected 21-inch monitor (GDM-500PST; Sony Corp., Tokyo, Japan; pixel RGB resolution, $1280 \times 965$; frame rate, $73 \mathrm{~Hz}$ ). Achromatic stimuli ranged in area from 0.01 to $2.67 \mathrm{deg}^{2}$, and chromatic stimuli ranged in area from 0.01 to $4.74 \mathrm{deg}^{2}$. Thresholds were measured at $10^{\circ}$ retinal eccentricity in four diagonal meridians $\left(36^{\circ}, 144^{\circ}, 216^{\circ}\right.$, $324^{\circ}$ ). Background luminance for achromatic tests was $10 \mathrm{~cd} / \mathrm{m}^{2}$. For the chromatic measurements, blue stimuli were presented on a black background on which the yellow light was superimposed by a semisilvered mirror, resulting in a luminance of $600 \mathrm{~cd} / \mathrm{m}^{2}$ at the eye. Stimulus duration was $200 \mathrm{~ms}$ for all detection tests.

Achromatic peripheral resolution acuity was also performed at the same locations using sinusoidal gratings with the same mean luminance as the background. Each maximum contrast grating stimulus $\left(3^{\circ}\right.$ diameter, 90\% contrast) was presented within a Gaussian window (SD, 1.5). Stimulus duration was 1 second, which included a $300 \mathrm{~ms}$ onset and $300 \mathrm{~ms}$ decay. Threshold was measured using an up/down staircase. Spatial frequency was increased by $10 \%$ after orientation was correctly identified three times in a row, and it was decreased by $10 \%$ after one incorrect response. Threshold was recorded as the average of four reversals.

Fixation was monitored visually for all experimental tests. Subjects were given a practice session on all psychophysical tests, and experimental tests were begun only when the subject and the examiner were confident that the task was understood.

\section{Statistical Analysis}

For any subject who had a TD $>-8 \mathrm{~dB}$ in one of the test locations (as measured by SAP), experimental data nearest this location was excluded and the spatial summation function for the remaining location in that hemifield was taken to represent that hemifield in further analysis. Once these points were excluded, the average TD for all test locations was $-1.3 \mathrm{~dB}$ (range, $+2 \mathrm{~dB}$ to $-8 \mathrm{~dB}$ ) for glaucoma patients and $+0.62 \mathrm{~dB}$ (range, $+4 \mathrm{~dB}$ to $-5 \mathrm{~dB}$ ) for healthy subjects. As an initial analysis, thresholds were averaged across subjects by hemifield (superior or inferior) for glaucoma patients and for controls and for each stimulus type. Two-phase regression analysis ${ }^{41}$ was performed (using SPSS, v15.0; SPSS Inc., Chicago, IL) on the averaged data to obtain estimates of Ricco's area. (See the accompanying paper for a more thorough explanation of the two-phase regression analysis. ${ }^{33}$ ) This analysis was then performed separately on the data from each hemifield for each subject and for each stimulus type. Estimates of Ricco's area were excluded from the study if the fit of the two-phase regression model did not reach the criterion of $r^{2}>0.9$

Measurements of resolution acuity were converted to estimates of ganglion cell sampling density using the method of Thibos et al. ${ }^{38}$ and assuming a hexagonal ganglion cell array. An association between Ricco's area (for each hemifield) and peripheral resolution acuity/ ganglion cell sampling density was sought by least squares linear regression analysis.

\section{Results}

Of the 48 local spatial summation curves generated for the glaucoma patients (24 superior, 24 inferior), four were excluded (two superior, two inferior) from the achromatic data and 10 were excluded (five superior, five inferior) from the chromatic data. Fifty-two local achromatic and 52 chromatic spatial summation curves (26 superior, 26 inferior) were generated for the healthy subjects. Of the 52 achromatic curves, two were excluded (both from the superior hemifield); for chromatic curves, eight were excluded (four superior, four inferior) from further analysis.

Figure 1 shows achromatic and chromatic stimulus spatial summation data, averaged across participants, for each hemifield and for patients and healthy subjects. A notable rightward displacement of the spatial summation curve can be seen for glaucoma patients, indicating an increase of Ricco's area compared with healthy subjects. There does not appear to be any sizable vertical displacement of the glaucoma curves compared with those of healthy subjects.

Mean thresholds for the smallest achromatic stimulus (0.01 $\mathrm{deg}^{2}$ ) were 0.6 and $0.45 \mathrm{log}$ units higher in glaucoma patients than in healthy subjects for the superior and inferior hemifields, respectively (independent samples $t$-test, $P<0.01$ ). Mean thresholds for the largest achromatic stimulus (2.67 $\mathrm{deg}^{2}$ ) were 0.18 and $0.14 \mathrm{log}$ units higher in glaucoma patients than in healthy subjects for the superior and inferior hemifields, respectively; however, this failed to reach significance $(P>0.05)$. For the chromatic stimuli, the differences in mean threshold between the glaucoma group and healthy subjects for the smallest reliable stimulus $\left(0.14 \mathrm{deg}^{2}\right)$ were 0.29 and $0.33 \log$ units for the superior and inferior hemifields, respectively $(P<0.01)$, but these difference decreased to -0.04 and $0.19 \log$ units and were insignificant for the largest stimulus $\left(4.74 \mathrm{deg}^{2}\right)$ in the superior and inferior hemifields, respectively $(P>0.05)$.

The two-phase models accounted for $>99 \%$ of the variance in the data in all cases retained in the analysis. The sizes of Ricco's area with the predicted $\log \Delta I / I$ at threshold under each experimental condition are summarized in Table 1.

Individual Ricco's area estimates from each subject under each condition are presented in Figure 2 for the superior and inferior hemifields. In each graph, the dotted line represents the size of the stimulus used in clinical perimetric instruments to detect functional loss in the respective visual pathways (see Fig. 2 legend). It can be seen from this figure that at these test locations, chromatic Ricco's area is, for the most part, smaller than the size of a Goldmann V stimulus, commonly used in SWAP. However, a sizable number of achromatic Ricco's areas have exceeded the size of a Goldmann III stimulus generally used in SAP. An independent samples $t$-test showed a significant difference between the means of the Ricco's area for the glaucoma and healthy groups for achromatic stimuli (superior, $P=0.004$; inferior, $P=0.01$ ). There is also a notable difference in the means of the Ricco's area between the two groups for chromatic stimuli. Although there is a statistically significant difference in Ricco's area between patients and healthy subjects for the inferior hemifield $(P=0.01)$, the difference did not reach statistical significance in the superior field $(P=$ 0.065). A paired $t$-test indicated that there was no significant hemifield difference in the size of Ricco's area for achromatic stimuli (glaucoma, $P=0.81$; controls, $P=0.47$ ) or for chromatic stimuli (glaucoma, $P=0.25$; controls, $P=0.59$ ).

Peripheral achromatic grating resolution acuity was significantly reduced in both hemifields for the glaucoma group compared with the age-similar healthy subjects (Fig. 3; superior field, $P<0.0001$; inferior field, $P<0.001$ ). Paired $t$-tests 
FiguRe 1. Average spatial summation functions for the glaucoma and healthy groups. Left: achromatic stimuli. Right: chromatic stimuli. Data for superior and inferior hemifields are shown. Vertical dotted lines: size of Ricco's area for each condition. Vertical error bars: $95 \%$ confidence intervals for each averaged point. Horizontal error bars: SEM of Ricco's area values.
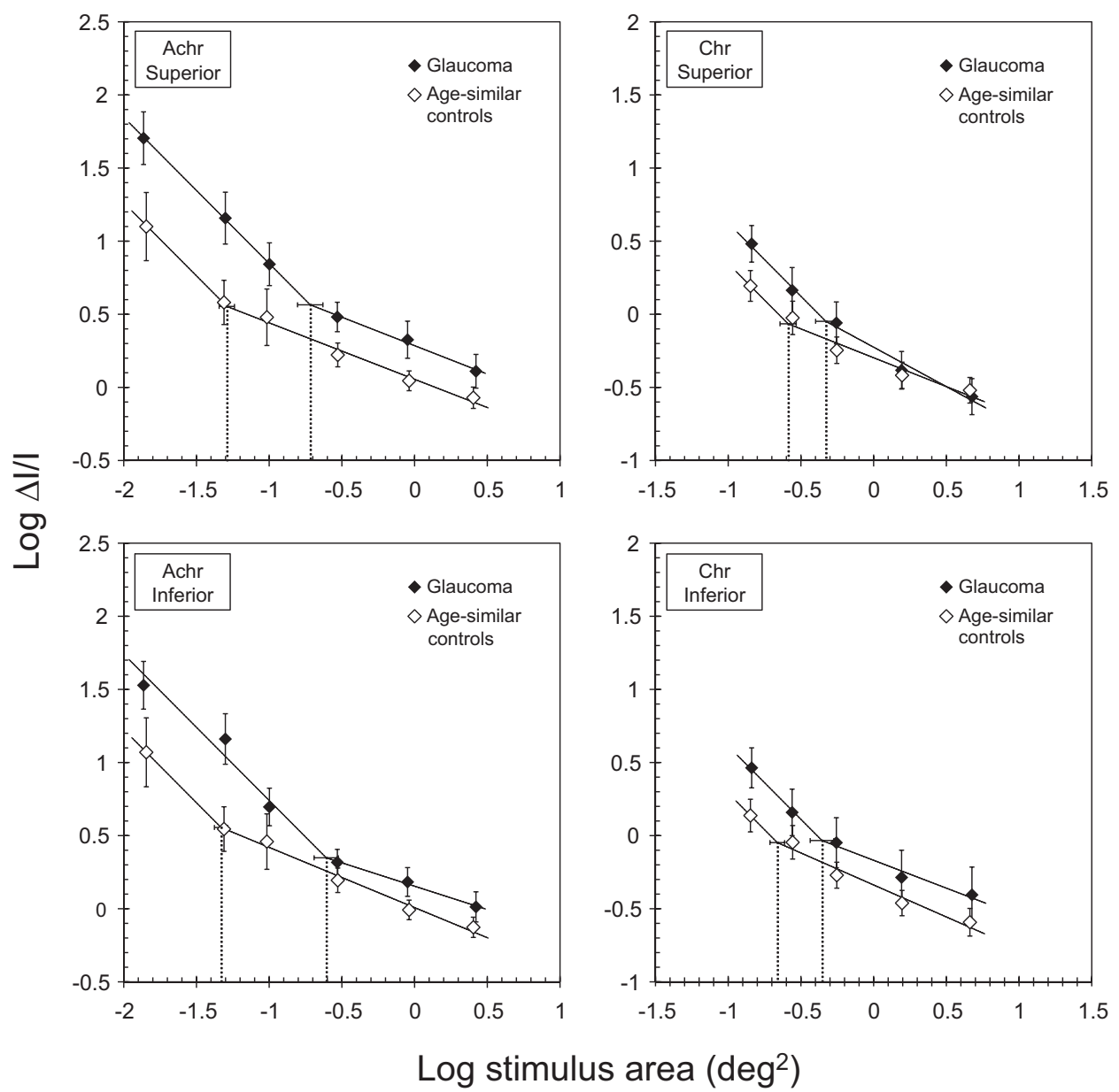

Log stimulus area $\left(\mathrm{deg}^{2}\right)$ showed no significant hemifield differences in either the glaucoma group $(P=0.72)$ or the healthy group $(P=0.58)$.

Figure $4 \mathrm{a}$ shows the relationship between peripheral resolution acuity and achromatic Ricco's area for all subjects, pooled across both hemifields. There is a significant, though relatively weak, relationship $\left(r^{2}=0.16\right)$. Figure $4 \mathrm{~b}$ shows the relationship between ganglion cell sampling density and values of Ricco's area.

\section{Discussion}

There was a significant increase in the size of Ricco's area in glaucoma patients compared with that of the age-similar healthy subjects for both achromatic and S-cone isolation conditions. There was also an associated significant decline in achromatic peripheral grating resolution acuity (and, hence, ganglion cell sampling density) in the glaucoma patients. It may be useful to consider the findings in the context of signal/ noise regulation in the visual system. As ganglion cell numbers decline in glaucoma, the retinal signal is reduced. If we assume that background cortical noise is constant, it might be that for a given "patch" of cortex, the retinal signal must be boosted to be detected within the noise. It might be that Ricco's area represents the required size of the patch to preserve detectability $\left(d^{\prime}\right)$, which needs the input of a critical number of ganglion cells. Therefore, with ganglion cell loss in glaucoma, a larger cortical patch may be necessary to maintain this detectability. There follows a discussion of our findings with reference to the theory of spatial summation and proposed physiological explanations for the phenomenon and the implications of the study results on perimetric stimulus design.

Disproportionate increases in mean detection threshold can be observed for small stimuli over large stimuli for glaucoma patients with respect to age-similar healthy subjects, reflecting complete spatial summation for small stimuli and probability summation for large stimuli. In Figure 5, it can be seen that the

TABLE 1. Values for Log Ricco's Area for Averaged Glaucoma and Healthy Subject Data, with Predicted Values of $\Delta I / I$ at Threshold for Ricco's Area

\begin{tabular}{llrrrr}
\hline & & \multicolumn{2}{c}{ Superior } & & \multicolumn{2}{c}{ Inferior } \\
\cline { 3 - 5 } Stimulus Type & \multicolumn{1}{c}{ Parameter } & Glaucoma & Healthy & Glaucoma \\
\hline \multirow{2}{*}{ Achromatic } & Log Ricco's area $\left(\mathrm{deg}^{2}\right)$ & -0.72 & -1.29 & -0.61 & Healthy \\
& Log $\Delta / / I$ & 0.56 & 0.55 & -1.33 \\
Chromatic & Log Ricco's area $\left(\mathrm{deg}^{2}\right)$ & -0.33 & -0.59 & -0.35 & -0.60 \\
& Log $\Delta I / I$ & -0.05 & -0.07 & -0.03 \\
\hline
\end{tabular}



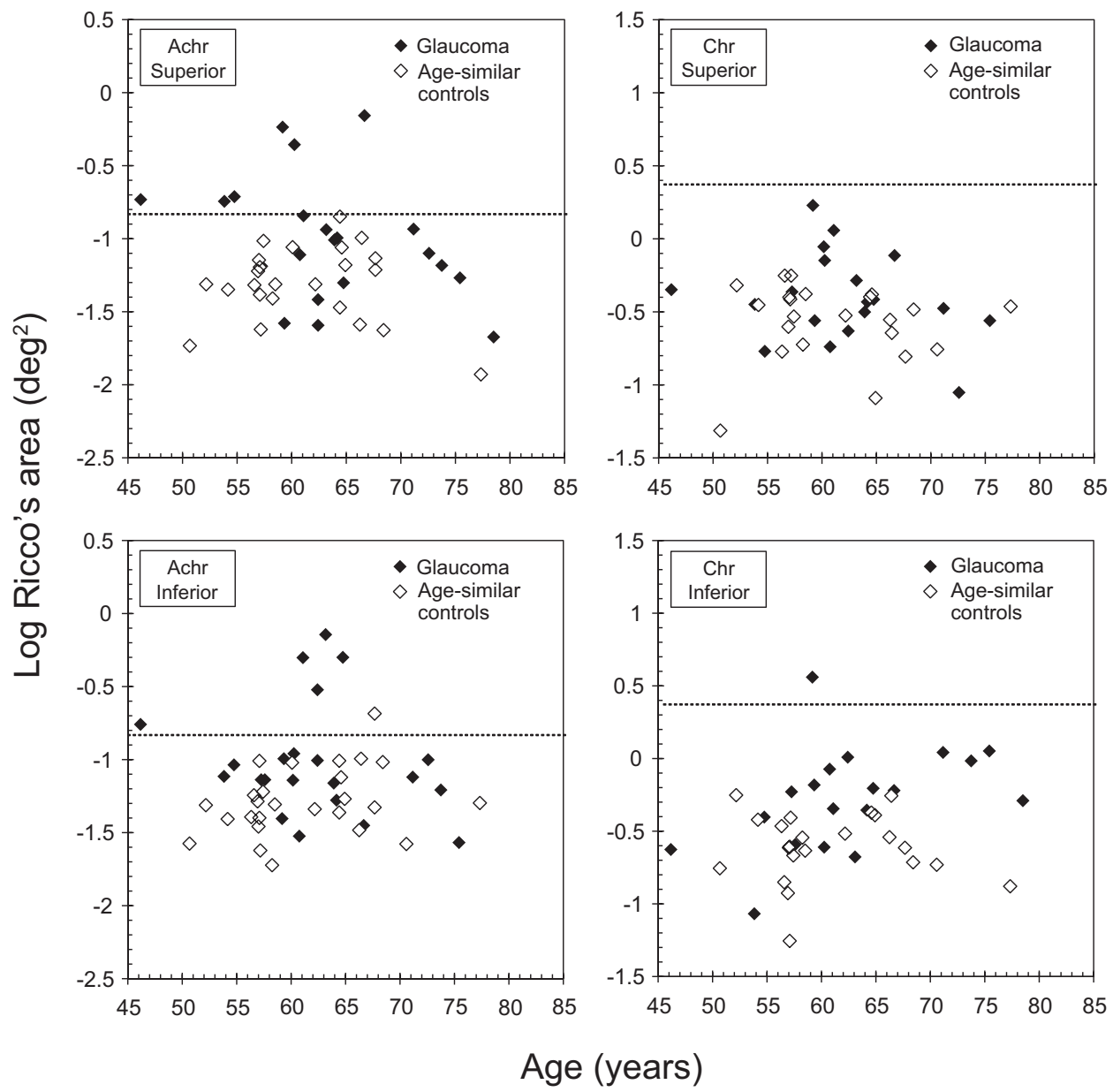

Figure 2. Individual Ricco's area estimates for glaucoma patients and age-similar healthy observers. Left: achromatic stimuli. Right: chromatic stimuli. The dotted line represents the size of a Goldmann III stimulus (used in SAP). Right: chromatic stimuli. The dotted line represents the size of a Goldmann V stimulus (used in SWAP).

spatial summation curves for glaucoma and healthy subjects can be made to overlap exactly if the glaucoma curve is translated leftward along the stimulus size axis. In other words, the sensitivity loss in early glaucoma can be recovered by an enlargement in stimulus size commensurate with Ricco's area. It follows that the predicted threshold at Ricco's area is largely the same between patients and healthy subjects. The mapping of the spatial summation curve for glaucoma patients onto that for healthy subjects (Fig. 5) mirrors exactly the lateral translation along the stimulus size axis required to superimpose spatial summation curves from the peripheral retina onto those from more central retinal areas in the healthy eye ${ }^{23}$ (i.e., a change in spatial scale ${ }^{20,42}$ ). The implication for perimetric testing in early glaucoma is that, if a stimulus is scaled in size in accordance with the changing extent of spatial summation, threshold sensitivity may be kept constant. Alternatively, if a fixed stimulus size is used, as in SAP, sensitivity to such a stimulus will decline, with the degree of decline dependent on the size of the stimulus relative to Ricco's area. Two questions arise as a result of the study findings. First, why does the area of complete spatial summation enlarge as functional ganglion cell density declines? Second, why is a decline in functional
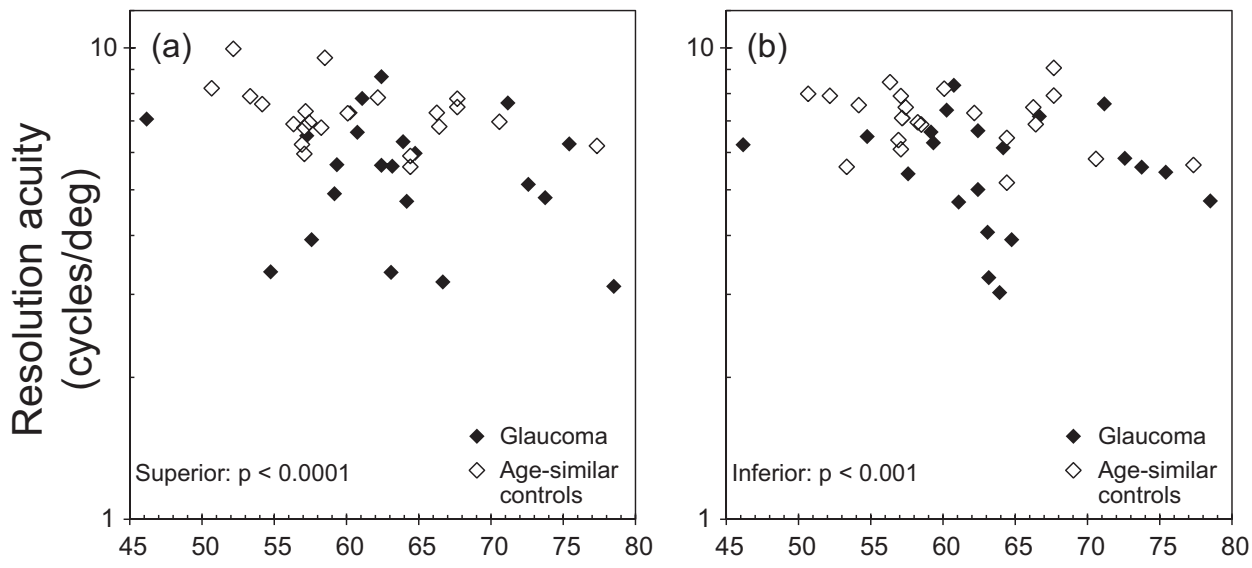

Age (years)
FIGURE 3. Achromatic peripheral grating resolution acuity for glaucoma patients and age-similar healthy subjects in the (a) superior and (b) inferior hemifield. 
FiguRe 4. Relationship between Ricco's area and (a) resolution acuity and (b) estimates of ganglion cell sampling density from resolution acuity measurements. All data are pooled across glaucoma patients and healthy subjects.
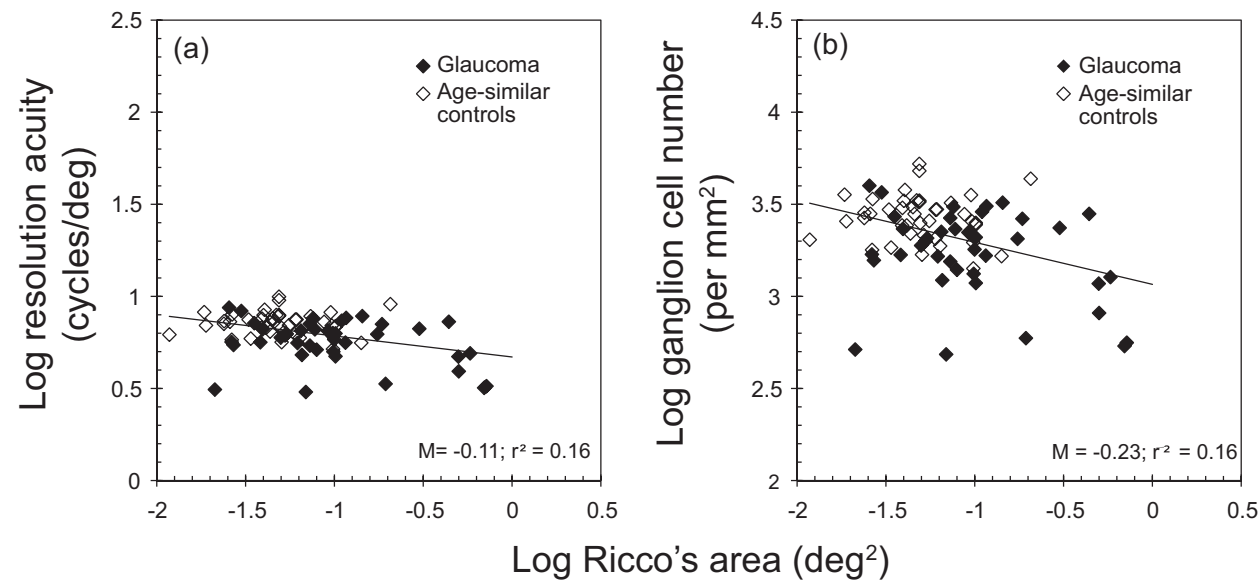

ganglion cell density not accompanied by a shift in the spatial summation curve along the sensitivity axis? Although optical quality has been shown to affect the size of Ricco's area in the fovea, ${ }^{30,43}$ the results of this study in the more peripheral visual field are unlikely to result from different age-related changes in optical quality because the ages of glaucoma patients and healthy subjects were evenly distributed over the same age range, and the accompanying paper indicates no appreciable change in Ricco's area with age. ${ }^{33}$ Furthermore, otherwise suitable participants were excluded if they had media opacities over and above those associated with normal aging. The results presented here, together with the findings of increasing Ricco's area with eccentricity, suggest that summation occurs over a constant number of retinal ganglion cells, irrespective of the area over which they are spaced. Schefrin et al. ${ }^{31}$ found an age-related enlargement of Ricco's area for circular increments under scotopic conditions, which they suggested was a result of retinal rewiring in response to agerelated retinal ganglion cell loss and, thus, greater convergence

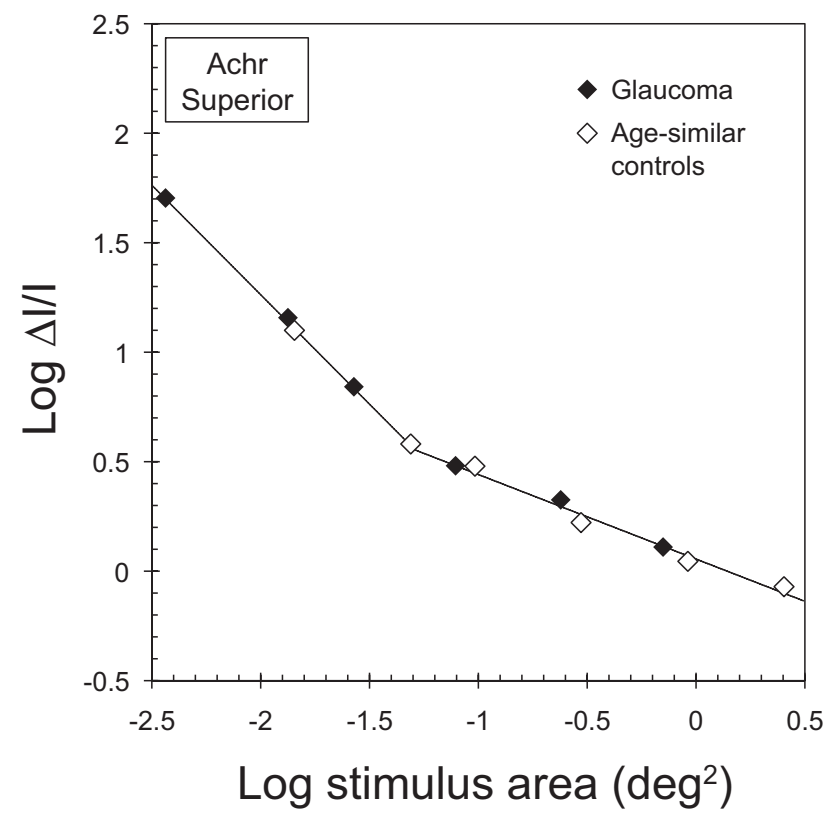

FIGURE 5. Average spatial summation functions for achromatic stimuli in the superior hemifield for glaucoma patients and age-similar healthy subjects overlap completely if the curve for the glaucoma group is displaced leftward along the size axis by an amount equal in magnitude to the difference in Ricco's area between the two groups. of photoreceptor signals onto remaining ganglion cells. Indeed, retinal remodeling has been observed in response to outer retinal degeneration ${ }^{44,45}$ and in glaucoma (at least in animal models). ${ }^{46-48}$ It is difficult to comprehend how changes in Ricco's area in glaucoma could be a result of increased pooling at a retinal level; however, ganglion cell shrinkage may occur in the early stages of the disease, ${ }^{48,49}$ and although Ricco's area has been purported to be associated with a constant number of ganglion cell dendritic fields, ${ }^{25}$ the relationship between these dendritic fields and their receptive fields $^{50}$ means that it is unlikely that retinal ganglion cells recruit lower level neurons in glaucoma. On the other hand, it may possible that the shrinkage of a retinal ganglion cell dendritic field reduces spatial antagonism from the receptive field surround. It can be seen from Figure 4 that the relationship between achromatic Ricco's area and achromatic peripheral grating resolution acuity, pooled across both patients and controls, is weak and that the slope of the relationship is shallow. This relationship may be partially explained by the different physical characteristics of the grating stimulus. In this study, we make use of a grating stimulus that subtends $3^{\circ}$ in diameter. With mild heterogenous loss (i.e., patchy loss of ganglion cells among retinal areas with more normal ganglion cell density), an area of low ganglion cell density might be dominated by the more normal areas underlying the grating. In addition, it might be that only healthy ganglion cells contribute to the detection of a spot stimulus near threshold, whereas both healthy and dysfunctional cells contribute to resolution of a high-contrast grating. Not only would this have the effect of weakening the relationship between resolution acuity and Ricco's area, it would also flatten the slope of the relationship.

If, after localized ganglion cell loss, higher neurons recruit input from different adjacent retinal ganglion cells, the qualitative properties of their receptive fields may be preserved while their output is quantitatively altered. Many studies that examine the relationship between structure and function in glaucoma have failed to consider higher level visual processing of conventional perimetric stimuli, exacerbating the weak structure/function relationships they find. Changes in Ricco's area with retinal eccentricity in the normal eye have previously been attributed to differences in spatial tuning by filters at a higher visual site. ${ }^{20,22,51}$ Because, in this study, there are changes in Ricco's area that resemble those seen with increased eccentricity in the healthy eye, it might be that the threshold in glaucoma is determined by altered pooling of signals by second-stage spatial filters over a wider area than in healthy subjects.

Several studies point toward plasticity in the visual cortex in response to glaucoma and other retinal damage. Gilbert and 
Wiesel $^{52}$ have previously reported an enlargement of retinotopically localized cortical receptive fields and their neighbors in the monkey model, in response to laser ablation of outer retinal cells. King et al. ${ }^{53}$ reported an enlargement of receptive fields at the level of the superior colliculus in response to experimental glaucoma (sustained elevation of IOP and retinal ganglion cell death) in rats. It is, as yet, speculative whether similar remodeling occurs in the human visual cortex in response to glaucoma or indeed whether it is even required to account for changes in Ricco's area.

Given the large population of human cortical cells compared with retinal ganglion cells (overall divergence), it seems unlikely that cortical cells or their receptive fields might enlarge to pool signals to compensate for retinal ganglion cell death. In fact, neural rewiring may not be necessary to pool signals over a larger area. To illustrate this point, it is worth bearing in mind the two-stage neural model of Swanson et al. ${ }^{20}$ This model predicts that at any part of the normal visual field, the number of retinal ganglion cells underlying Ricco's area (for those relevant adaptive conditions) is approximately 31 . In the visual cortex, there may be cells that vary in the number of ganglion cells that feed forward to them. For the purposes of explanation, we will call these cells A, B, and C (see schematic in Fig. 6). We shall assume that these cells are concentric and differ in spatial extent. Some cells may receive input from exactly 31 cells (cell B), whereas others may be larger and may receive input from more (cell $\mathrm{C}$ ) or smaller cells and may receive input from fewer cells (cell A). Because cell $B$ is the largest cell that satisfies the conditions for complete spatial summation, its receptive field determines the size of Ricco's area. Next we consider a scenario in which the two cells, $B$ and $\mathrm{C}$, receive input from 31 and 40 ganglion cells, respectively, assuming that the same 31 ganglion cells that connect to cell $\mathrm{B}$ also connect to cell C, along with other adjacent ganglion cells. If nine ganglion cells in this region are lost due to glaucoma, cell B now receives input from only 22 ganglion cells. Similarly, cell $\mathrm{C}$ now receives input from only 31 ganglion cells. This cell now satisfies the conditions for complete spatial summation; its receptive field size determines the size of Ricco's area and maintains a constant signal/noise ratio. Indeed, a confident acceptance or rejection of this hypothesis requires an investigation by cellular recording at a cortical level in glaucoma.

The results presented are for patients with early glaucoma, and most of our test locations were classified as having $>5 \%$ probability of normality by standard automated perimetry. It is not possible to extrapolate the findings to more severe damage; there may be a limit to the extent to which an enlargement of Ricco's area can compensate for ganglion cell loss. As the disease state advances, and as ganglion cell numbers inputting to cells in the cortex become fewer, the spatial summation curve might undergo an eventual vertical displacement (i.e., along the intensity axis). Further experimentation is required to define the limits of enlargement of Ricco's area.

The enlargement of Ricco's area in early glaucoma has implications for the evaluation of results from SAP and the design of appropriate perimetric stimuli. In light of our findings, we propose that the two-stage (hockey stick) neural model describing the physiological relationship between ganglion cell density and perimetric thresholds in the normal eye $\mathrm{e}^{20}$ can be extended to determine ganglion cell numbers from perimetric thresholds in early glaucoma. Under this model, perimetric sensitivity declines with a slope of $2.5 \mathrm{~dB}$ per $\log$ unit decline in ganglion cell numbers until Ricco's area exceeds the size of a Goldmann III; sensitivity at this point is 31.5 $\mathrm{dB}$ and then declines at a rate of $10 \mathrm{~dB}$ per log unit reduction in ganglion cell number. Such a nonlinear relationship may also account for differences in test-retest variability observed in advanced glaucoma compared with early glaucoma for different stimulus sizes. ${ }^{54-56}$ Anderson $^{21}$ recommended that conventional stimuli should modulate to exploit changes in Ricco's area in glaucoma, if found. Although stimuli used in SAP and SWAP are of a fixed size and are modulated in contrast only, it is evident that the size of the stimulus in relation to the spatial summation curve must be considered to interpret the magnitude of related neural loss for differently sized stimuli and the relevance of accompanying variability. The findings also support an approach for perimetry in which stimuli within Ricco's area are modulated in size (either alone or simultaneously with contrast) with the aspiration to boost the glaucoma signal. This would give the advantage of operating under conditions in which the ratio of ganglion cell density/function is $1: 1$ while also normalizing the test-retest variability across the range of glaucoma. This requires further experimental evaluation however. Could test-retest variability in the damaged retina be lower for size-modulated stimuli than for intensity-modulated stimuli? Such a finding could enhance the glaucoma signal while keeping measurement noise to a minimum.

Interestingly, for the glaucoma patients in this study and at the locations tested, chromatic Ricco's area remains, for the most part, smaller than a Goldmann V stimulus, whereas in many patients, Ricco's area for achromatic stimuli exceeded the size of a Goldmann III stimulus (Fig. 2). If the hockey stick model is applied to the S-cone pathway, our results imply that, for these patients, while achromatic Ricco's area is larger than

\section{Healthy eye}

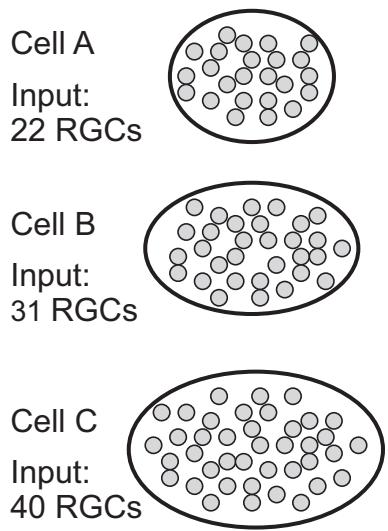

Threshold

$<31 \mathrm{~dB}$

Complete

spatial

summation

$31 \mathrm{~dB}$

Complete

spatial

summation

$>31 \mathrm{~dB}$

Probability summation
Glaucoma

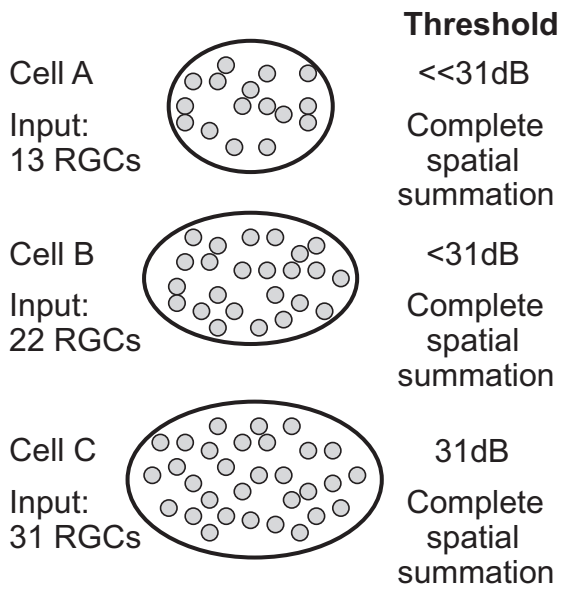

Figure 6. Cells A, B, and C represent a subset of cortical filters centered on the same retinal location. Left: healthy state. Right: after loss of RGCs. Ricco's area is determined by the filter with an input of approximately 31 RGCs (filter $B$ in the healthy state and filter $\mathrm{C}$ in the case of RGC loss). Sensitivity at Ricco's area is approximately $31.5 \mathrm{~dB}$. 
the Goldmann III and chromatic Ricco's area is smaller than the Goldmann V, achromatic loss exceeds chromatic loss at the same stage of disease.

In conclusion, Ricco's area enlarges in early glaucoma for achromatic and S-cone specific stimuli. Perimetric stimuli that modulate in size during testing may have advantages over those that modulate only in intensity.

\section{Acknowledgments}

The authors thank David P. Crabb for statistical advice.

\section{References}

1. Quigley HA, Addicks EM, Green WR. Optic nerve damage in human glaucoma, III: quantitative correlation of nerve fiber loss and visual field defect in glaucoma, ischemic neuropathy, papilledema, and toxic neuropathy. Arch Ophthalmol. 1982;100:135146.

2. Quigley HA, Sanchez RM, Dunkelberger GR, L'Hernault NL, Baginski TA. Chronic glaucoma selectively damages large optic nerve fibers. Invest Ophthalmol Vis Sci. 1987;28:913-920.

3. Quigley HA, Dunkelberger GR, Green WR. Retinal ganglion cell atrophy correlated with automated perimetry in human eyes with glaucoma. Am J Ophthalmol. 1989;107:453-464.

4. Harwerth RS, Carter-Dawson L, Shen F, Smith EL 3rd, Crawford ML. Ganglion cell losses underlying visual field defects from experimental glaucoma. Invest Ophthalmol Vis Sci. 1999;40:22422250.

5. Kerrigan-Baumrind LA, Quigley HA, Pease ME, Kerrigan DF, Mitchell RS. Number of ganglion cells in glaucoma eyes compared with threshold visual field tests in the same persons. Invest Ophthalmol Vis Sci. 2000;41:741-748.

6. Harwerth RS, Vilupuru AS, Rangaswamy NV, Smith EL 3rd. The relationship between nerve fiber layer and perimetry measurements. Invest Ophthalmol Vis Sci. 2007;48:763-773.

7. Schuman JS, Hee MR, Puliafito CA, et al. Quantification of nerve fiber layer thickness in normal and glaucomatous eyes using optical coherence tomography. Arch Ophthalmol. 1995;113:586-596.

8. Caprioli J. Early diagnosis of functional damage in patients with glaucoma. Arch Ophthalmol. 1997;115:113-114.

9. Bowd C, Weinreb RN, Williams JM, Zangwill LM. The retinal nerve fiber layer thickness in ocular hypertensive, normal, and glaucomatous eyes with optical coherence tomography. Arch Ophthalmol. 2000;118:22-26.

10. El Beltagi TA, Bowd C, Boden C, et al. Retinal nerve fiber layer thickness measured with optical coherence tomography is related to visual function in glaucomatous eyes. Ophthalmology. 2003; 110:2185-2191.

11. Kanamori A, Nakamura M, Escano MF, Seya R, Maeda H, Negi A. Evaluation of the glaucomatous damage on retinal nerve fiber layer thickness measured by optical coherence tomography. Am J Ophthalmol. 2003;135:513-520.

12. Bowd C, Zangwill LM, Medeiros FA, et al. Structure-function relationships using confocal scanning laser ophthalmoscopy, optical coherence tomography, and scanning laser polarimetry. Invest Ophthalmol Vis Sci. 2006;47:2889-2895.

13. Hood DC, Kardon RH. A framework for comparing structural and functional measures of glaucomatous damage. Prog Retin Eye Res. 2007;26:688-710.

14. Quigley HA, Dunkelberger GR, Green WR. Chronic human glaucoma causing selectively greater loss of large optic nerve fibers. Ophthalmology. 1988;95:357-363.

15. Garway-Heath DF, Caprioli J, Fitzke FW, Hitchings RA. Scaling the hill of vision: the physiological relationship between light sensitivity and ganglion cell numbers. Invest Ophthalmol Vis Sci. 2000; 41:1774-1782.

16. Garway-Heath DF, Holder GE, Fitzke FW, Hitchings RA. Relationship between electrophysiological, psychophysical, and anatomical measurements in glaucoma. Invest Ophthalmol Vis Sci. 2002; 43:2213-2220.

17. Schlottmann PG, De Cilla S, Greenfield DS, Caprioli J, GarwayHeath DF. Relationship between visual field sensitivity and retinal nerve fiber layer thickness as measured by scanning laser polarimetry. Invest Ophthalmol Vis Sci. 2004;45:1823-1829.

18. Harwerth RS, Quigley HA. Visual field defects and retinal ganglion cell losses in patients with glaucoma. Arch Ophthalmol. 2006;124: 853-859.

19. Malik R, Swanson WH, Garway-Heath DF. Development and evaluation of a linear staircase strategy for the measurement of perimetric sensitivity. Vision Res. 2006;46:2956-2967.

20. Swanson WH, Felius J, Pan F. Perimetric defects and ganglion cell damage: interpreting linear relations using a two-stage neural model. Invest Ophthalmol Vis Sci. 2004;45:466-472.

21. Anderson RS. The psychophysics of glaucoma: improving the structure/function relationship. Prog Retin Eye Res. 2006;25: 79-97.

22. Pan F, Swanson WH. A cortical pooling model of spatial summation for perimetric stimuli. J Vis. 2006;6:1159-1171.

23. Wilson ME. Invariant features of spatial summation with changing locus in the visual field. J Physiol. 1970;207:611-622.

24. Volbrecht VJ, Shrago EE, Schefrin BE, Werner JS. Spatial summation in human cone mechanisms from 0 degrees to 20 degrees in the superior retina. J Opt Soc Am A Opt Image Sci Vis. 2000;17: 641-650.

25. Vassilev A, Ivanov I, Zlatkova MB, Anderson RS. Human S-cone vision: relationship between perceptive field and ganglion cell dendritic field. J Vision. 2005;5:823-833.

26. Brindley GS. The summation areas of human colour-receptive mechanisms at increment threshold. J Physiol. 1954;124:400408.

27. Barlow HB. Temporal and spatial summation in human vision at different background intensities. J Physiol. 1958;141:337-350.

28. Glezer VD. The receptive fields of the retina. Vision Res. 1965;5: 497-525.

29. Brindley GS. Physiology of the Retina and Visual Pathway. 2nd ed. London: Edward Arnold; 1970:xi.

30. Davila KD, Geisler WS. The relative contributions of pre-neural and neural factors to areal summation in the fovea. Vision Res. 1991; 31:1369-1380.

31. Schefrin BE, Bieber ML, McLean R, Werner JS. The area of complete scotopic spatial summation enlarges with age. J Opt Soc Am A Opt Image Sci Vis. 1998;15:340-348.

32. Dannheim F, Drance SM. Studies of spatial summation of central retinal areas in normal people of all ages. Can J Ophthalmol. 1971;6:311-319.

33. Redmond T, Zlatkova MB, Garway-Heath DF, Anderson RS. The effect of age on the area of complete spatial summation for chromatic and achromatic stimuli. Invest Ophthalmol Vis Sci. 2010;51: 6533-6539.

34. Fellman RL, Lynn JR, Starita RJ, Swanson WH. Clinical importance of spatial summation in glaucoma. In: Heijl A, ed. Perimetry Update 1988/1989. Amsterdam: Kugler and Gedini: 1989:313324.

35. Dannheim F, Drance SM. Psychovisual disturbances in glaucoma: a study of temporal and spatial summation. Arch Ophthalmol. 1974; 91:463-468.

36. Felius J, Swanson WH, Fellman RL, Lynn JR, Starita RJ. Spatial summation for selected ganglion cell mosaics in patients with glaucoma. In: Wall M, Heijl A, eds. Perimetry Update 1996/1997 Proceedings of the XIIth International Perimetric Society Meeting. Amsterdam: Kugler: 1997:213-221.

37. Battista J, Badcock DR, McKendrick AM. Spatial summation properties for magnocellular and parvocellular pathways in glaucoma. Invest Ophthalmol Vis Sci. 2009;50:1221-1226.

38. Thibos LN, Cheney FE, Walsh DJ. Retinal limits to the detection and resolution of gratings. J Opt Soc Am A. 1987;4:1524-1529.

39. Anderson RS, Zlatkova MB, Demirel S. What limits detection and resolution of short-wavelength sinusoidal gratings across the retina? Vision Res. 2002;42:981-990.

40. Pentland A. Maximum likelihood estimation: the best PEST. Percept Psychophys. 1980;28:377-379.

41. Seber GAF, Wild CJ. Nonlinear Regression. New York: John Wiley \& Sons; 1989. 
42. Latham K, Whitaker D, Wild JM, Elliott DB. Magnification perimetry. Invest Opbthalmol Vis Sci. 1993;34:1691-1701.

43. Dalimier E, Dainty C. Role of ocular aberrations in photopic spatial summation in the fovea. Opt Lett. 2010;35:589-591.

44. Marc RE, Jones BW, Watt CB, Strettoi E. Neural remodeling in retinal degeneration. Prog Retin Eye Res. 2003;22:607-655.

45. Jones BW, Watt CB, Marc RE. Retinal remodelling. Clin Exp Optom. 2005;88:282-291.

46. Ahmed FA, Chaudhary P, Sharma SC. Effects of increased intraocular pressure on rat retinal ganglion cells. Int J Dev Neurosci. 2001;19:209-218.

47. Jakobs TC, Libby RT, Ben Y, John SW, Masland RH. Retinal ganglion cell degeneration is topological but not cell type specific in DBA/2J mice. J Cell Biol. 2005;171:313-325.

48. Morgan JE, Datta AV, Erichsen JT, Albon J, Boulton ME. Retinal ganglion cell remodelling in experimental glaucoma. Adv Exp Med Biol. 2006;572:397-402.

49. Morgan JE. Retinal ganglion cell shrinkage in glaucoma. J Glaucoma. 2002;11:365-370.

50. Peichl L, Wässle $H$. The structural correlate of the receptive field centre of alpha ganglion cells in the cat retina. J Pbysiol. 1983; 341:309-324.
51. Pan F, Swanson WH, Dul MW. Evaluation of a two-stage neural model of glaucomatous defect: an approach to reduce test-retest variability. Optom Vis Sci. 2006;83:499-511.

52. Gilbert CD, Wiesel TN. Receptive field dynamics in adult primary visual cortex. Nature. 1992;356:150-152.

53. King WM, Sarup V, Sauve Y, Moreland CM, Carpenter DO, Sharma SC. Expansion of visual receptive fields in experimental glaucoma. Vis Neurosci. 2006;23:137-142.

54. Artes PH, Iwase A, Ohno Y, Kitazawa Y, Chauhan BC. Properties of perimetric threshold estimates from Full Threshold, SITA Standard, and SITA Fast strategies. Invest Opbthalmol Vis Sci. 2002;43: 2654-2659.

55. Artes PH, Hutchison DM, Nicolela MT, LeBlanc RP, Chauhan BC. Threshold and variability properties of matrix frequency-doubling technology and standard automated perimetry in glaucoma. Invest Ophthalmol Vis Sci. 2005;46:2451-2457.

56. Wall M, Woodward KR, Doyle CK, Artes PH. Repeatability of automated perimetry: a comparison between standard automated perimetry with stimulus size III and V, matrix, and motion perimetry. Invest Opbthalmol Vis Sci. 2009;50:974979 